\title{
Effects of knife shapes and cutting speeds of a mower on the percentage pulverization of sweet potato vine
}

\begin{abstract}
The effects of a rotary slasher with two different shapes of knives (L and Y-shaped) at three cutting speeds (1830, 2066 and $2044 \mathrm{rpm}$ ) were studied on percentage of pulverization of sweet potato vine passing through the sieve $(<28 \mathrm{~mm} 2)$. The results showed that all the treatments were significant at p 0.05 and p 0.01 significance level. The best result was by Yshaped knife with highest vine pulverized percentage of $82.76 \%$ and a mower speed of 2440 $\mathrm{rpm}$ had the finest vine pulverized percentage of $90.48 \%$. The best performance for interaction effects between knife shapes and speeds of mower was achieved by the Y-shaped knife and a mower speed of $2440 \mathrm{rpm}$ resulting in an average percentage of $92.62 \%$ of pulverized vine.
\end{abstract}

Keyword: Cutting; Knife shapes; Mower; Pulverization; Slasher; Speed; Sweet potato 